\title{
LA REFORMA DEL ARTÍCULO 135 DE LA CARTA MAGNA ESPAÑOLA \\ (La superación de los clichés del tabú y de la rigidez constitucionales)
}

LUIS JIMENA QUESADA

Catedrático de Derecho constitucional

Universidad de Valencia

SUMARIO

I. Consideraciones preliminares: otra reforma constitucional (innecesaria) impuesta desde la Unión Europea.

II. El economicismo timorato como pretexto de la superación del tabú de la reforma constitucional.

III. El europeísmo conveniente como causa de la flexibilidad del procedimiento de reforma constitucional.

IV. La relativización del ejercicio del poder constituyente soberano y la relegación del lugar de la ciudadanía.

V. Reflexiones finales: la reforma constitucional de 2011 como agravio comparativo y signo de europeización de la función constituyente.

\section{CONSIDERACIONES PRELIMINARES: OTRA REFORMA CONSTITUCIONAL (INNECESARIA) IMPUESTA DESDE LA UNIÓN EUROPEA}

En el presente trabajo se abordará críticamente, en clave de teoría constitucional europea, la reciente reforma del artículo 135 de la Constitución española de 1978 (CE), de septiembre de 2011. Ya de entrada, varios aspectos de la nueva redacción de dicha disposición constitucional llaman la atención: ante todo, que la primera vez que nuestro Texto constitucional alude explícitamente a la Unión Europea (UE) lo sea para afectar a la 
«constitución económica» y para limitar de modo meridiano el ejercicio de competencias soberanas en aras del principio de estabilidad presupuestaria ${ }^{1} ; y$, en segundo término, que la puesta en práctica del nuevo artículo 135 CE genera un enorme grado de inseguridad jurídica al quedar al albur de no pocas remisiones jurídico-políticas (límites fijados por la UE o por el TFUE; una o varias reservas de ley orgánica en materia de déficit estructural máximo o de desarrollo de los subprincipios de estabilidad presupuestaria ${ }^{2}$; el juego del margen de apreciación estatal en la superación excepcional de los límites establecidos mediante autorización de la mayoría absoluta del Congreso de los Diputados; el despliegue border line de un marco discrecional estatutario por parte de las Comunidades Autónomas, y la laxitud temporal de una eficacia del límite de déficit estructural diferida en casi una década ${ }^{3}$ ).

Como es sabido, y lógicamente por la ubicación del precepto en el Texto constitucional, la reforma se ha operado por la vía del artículo $167 \mathrm{CE}$, siendo adoptada tanto en el Congreso como en el Senado por una amplísima mayoría que parece evocar un consenso nada desdeñable. Desde esta perspectiva, posiblemente lo más destacable de la reforma del artículo 135 CE sea el pacto para su adopción entre los dos grandes partidos con representación parlamentaria, cuando menos en términos de democracia procedimental. En efecto, se habría escenificado la vía consensual precisa para la reforma de la Carta Magna, como prolongación del consenso que presidió su adopción en 1978 tras el proceso constituyente.

Ahora bien, en mi opinión, seguramente ese fácil consenso bipartidista sea al tiempo lo más preocupante del acelerado procedimiento de reforma del artículo $135 \mathrm{CE}$, pues revela un resignado pacto constituyente impuesto desde Europa y derivado del hasta ahora generalmente criticado — en la doctrina constitucionalista-Estado de partidos, lo cual a su vez presenta connotaciones de una deriva europeísta y partidista alejada de la voluntad popular y, por ende, de cánones claros de democracia sustancial ${ }^{4}$.

1 Efectivamente, entre los ocho signos distintivos del poder soberano, según Bodino, tres de ellos (el derecho de acuñar moneda, la determinación de los pesos y medidas, y el derecho de recaudar impuestos) entroncan directamente con la idea de «constitución económica» que actualmente se encuentran limitados por mor de la integración europea: véase SÁNCHEZ FERRIZ, R.: Introducción al Estado constitucional, Barcelona, Ariel, 1993, págs. 221-225: la citada autora añade un ingrediente de especial relevancia en el contexto actual de crisis, que no sólo es económica, sino asimismo de confianza por el degradado ambiente de corrupción e irresponsabilidad políticas: «tal vez el más interesante de los límites [de la soberanía, según Bodino] desde el punto de vista político es el que se deriva de la propia naturaleza del Estado y de la legitimidad que el propio príncipe habrá de conservar con su recto comportamiento y con el cumplimiento de la palabra dada, ya sea a sus súbditos, ya a sus iguales representantes de otros Estados» (p. 223).

2 Mientras que de los apartados 2 y 5 del artículo 135 CE parece desprenderse la posibilidad de dos leyes orgánicas distintas, la Disposición adicional única de la reforma singulariza «la Ley Orgánica prevista en el artículo $135 »$.

3 A tenor del apartado 3 de la Disposición adicional única de la reforma, según la cual «Los límites de déficit estructural establecidos en el artículo 135.2 de la Constitución Española entrarán en vigor a partir de 2020». Desde la perspectiva de la técnica legislativa, algún grupo parlamentario (Sr. Durán i Lleida, por CiU, DSCD, IX Legislatura, 30 de agosto de 2011, $\mathrm{n}^{\circ} 269$, pág. 8) sugirió que este apartado quedara formalizado como una Disposición transitoria. En este marco, en la doctrina se ha reprochado que la pretendida urgencia de la reforma del artículo $135 \mathrm{CE}$ se cohonesta mal con la demora de su eficacia al año 2020: así, BLANCO VALDÉS, R.: «La reforma de 2011: de las musas al teatro», Claves de la razón práctica, n 216, octubre 2011, pág. 17.

4 En palabras kelsenianas (Esencia y valor de la democracia, Madrid, Guadarrama, 1977), no basta con apelar al pueblo de modo más o menos periódico (a intervalos regulares cada cuatro años, más o menos) en su condición de electorado (democracia procedimental), sino en contar con aquél en el ejercicio y vigencia cotidianos de los derechos 
Diversos signos demuestran la preocupación a la que aludo. Por lo pronto, el núcleo de la reforma se ha llevado a cabo en agosto de 2011, precisamente en el mes en que ha podido pasar más desapercibida a la opinión pública, lo que desgraciadamente rememora prácticas de convocatorias de procesos de acceso a la función pública orientados a evitar una concurrencia real (mutatis mutandis, un debate público en condiciones). En la misma línea, se ha prescindido de la consulta popular (posible a tenor del artículo $167 \mathrm{CE}$, pero impracticable al haber apostado por ella partidos políticos con insuficiente representación parlamentaria a los efectos de dicha disposición constitucional $)^{5}$, pese a tratarse de una reforma con evidente trasfondo constitucional europeo (lo que, dicho sea de paso, contrasta con el referéndum consultivo celebrado el 20 de febrero de 2005 para apoyar el frustrado Tratado constitucional por el que se establecía una Constitución para Europa, apoyo que fue mostrado asimismo de forma entusiasta por los dos grandes partidos políticos españoles) ${ }^{6}$.

Estos signos de índole procedimental se han visto acompañados de otros elementos preocupantes de orden sustancial. Así, se ha acudido a la reforma constitucional (concebida como una garantía o mecanismo de defensa de la propia Constitución ${ }^{7}$, lo mismo que la jurisdicción constitucional ${ }^{8}$ ) como remedio anticrisis, lo cual desacredita a nuestra clase política, incapaz de haber tomado con antelación (incluso en el contexto de la crisis económica y financiera, intentando atajarla desde el inicio) las medidas socio-económicas precisas para apuntalar el modelo productivo. De hecho, el haber tocado la «constitución económica», pese a su misma flexibilidad ${ }^{9}$, mediante su reforma acredita, además de la aparente facilidad para superar el tabú de la reforma constitucional, la fragilidad de las

y libertades (democracia sustancial). En realidad, ni siquiera se trata de que las decisiones jurídicas y políticas más relevantes las adoptemos todos (democracia plebiscitaria) ni mucho menos que todos estemos de acuerdo, sino que todos tengamos la oportunidad de participar de forma directa o por medio de representantes (democracia deliberativa): BASTIDA FREIJEDO, F.J.: «La soberanía borrosa: la democracia», Fundamentos. Cuadernos monográficos de Teoría del Estado, Derecho Público e Historia Constitucional, Oviedo, Junta General del Principado, 1998, pág. 450.

5 PRESNO LINERA, M.A.: «El 15M y la democracia real», El Cronista del Estado Social y Democrático de Derecho, $\mathrm{n}^{\circ} 25$, enero 2012, pág. 45: «La "deslealtad democrática” a los ciudadanos es especialmente grave cuando la ausencia de debate o el empleo de una fórmula inadecuada se refiere no ya a la aprobación de una concreta disposición legal, por relevante que sea, sino a un cambio radical en la orientación política del Gobierno o una modificación de la Norma Constitucional».

6 Tras una campaña llena de banalidades, los datos mostraron una incuestionable victoria del sí $(76,73 \%)$ entre los votos emitidos. Sin embargo, no puede ignorarse que el porcentaje de participación fue el más bajo de nuestra historia democrática $(43,32 \%)$, por debajo, incluso, de la exigua afluencia de votantes en las elecciones al Parlamento Europeo de junio de 2004 (45,94\%). Así las cosas, y sobre el total del censo electoral (34.687.888), sólo el 31,14\% votó a favor del Tratado constitucional. La misma sensación se percibe tras la aprobación en sede parlamentaria de la Ley Orgánica 1/2005 de 20 de mayo, por la que se autoriza la ratificación del Tratado por parte de España. El que, en las Cortes Generales, dicha ley obtuviera el 88,85\% de votos a favor en el Congreso (311 sobre un total de 350), y el 87,20\% en el Senado (225 sobre un total de 258), frente al mencionado $31,14 \%$ de apoyo popular, habla bien a las claras, una vez más, del abismo existente entre la ciudadanía y la clase política que supuestamente la representa.

7 Por tal motivo, en la doctrina española se ha criticado la posible utilización de la conocida como «reforma de doble grado», esto es, reformar el procedimiento de reforma para hacerlo menos exigente y, por ende, supuestamente menos «defensor» del orden constitucional: así, DE OTTO PARDO, I.: Derecho Constitucional. Sistema de fuentes, Barcelona, Ariel, $4^{\mathrm{a}}$ reimpr. 1995, pág. 66: «no sería posible que mediante el procedimiento previsto en el art. 167 se reformase el art. 168, por ejemplo para dar menor rigidez a los preceptos a que éste se refiere. Tampoco aquí habría aplicación de una norma a sí misma, pero se estaría alterando la relación que subordina el art. 167 al 168 y resultaría un patente fraude del sistema de reforma». 
medidas económicas adoptadas con arreglo a parámetros de normalidad constitucional, esto es, a través de leyes o normas con fuerza de ley (epígrafe II, infra).

Resulta llamativo que en una Legislatura (la IX, segunda bajo el Gobierno del Presidente Rodríguez Zapatero) marcada por la crisis económica y por la percepción de interinidad de los gobernantes (provisionalidad certificada en los resultados de las elecciones del 20 de noviembre de 2012 que dieron la mayoría absoluta al Partido Popular y la Presidencia del Gobierno a Rajoy Brey) y, en consecuencia, parca en adopción de leyes y otras fuentes normativas consensuadas, haya mediado un amplio pacto político no sólo para poner en práctica la excepcional reforma constitucional (la segunda de nuestra Ley Suprema de 1978), sino asimismo para recurrir por vez primera (en diciembre de 2010) a los estados de anormalidad constitucional previstos en el artículo $116^{10}$. En realidad, este paralelismo es tanto más pertinente cuanto que la declaración del estado de alarma en diciembre de 2010 tiene igualmente como telón de fondo la debilidad de nuestro modelo productivo, en este caso para encauzar con la antelación suficiente la negociación colectiva en el sector controvertido (sin justificar obviamente el inmenso daño personal y material causado por los controladores del tráfico aéreo $)^{11}$.

Naturalmente, la pertenencia a la UE no implica únicamente la adopción ordinaria de leyes y otras normas nacionales, sino que puede comportar asimismo la excepcional necesidad de una reforma constitucional: al no constituir el objeto del presente estudio, me limitaré a constatar que la reforma de 1992 sí fue necesaria al dictaminarlo así el Tribunal Constitucional (TC) mediante su Declaración de 1 de julio de 1992 en materia de sufragio pasivo en elecciones municipales según lo exigido por el Tratado de Maastricht ${ }^{12}$. Al contrario, la reforma del artículo $135 \mathrm{CE}$ no era necesaria ni en términos de adaptación al ordenamiento de la UE ni en clave de exigencia normativa interna, proyectando más bien un extraño alarde de europeísmo que ha puesto claramente en entredicho la idea doctrinal imperante del procedimiento especial de reforma como causa de la rigidez o la

8 A este respecto, se ha señalado que la rigidez constitucional habría constituido el presupuesto teórico ineludible para el ulterior establecimiento de fórmulas de control de constitucionalidad, como mecanismo asimismo (igual que la reforma constitucional) de defensa de la Norma Suprema: por todos, DE VEGA, P.: La reforma constitucional y la problemática del Poder Constituyente, Madrid, Tecnos, 1ª ed., reimpr., 1988, pág. 70.

9 Sobre el particular, expresó DE LA QUADRA-SALCEDO, T.: «La Constitución económica de España. Comentario introductorio al Título VII», en Comentarios a la Constitución española de 1978 (dir. O. ALZAGA VILLAAMIL), tomo X, Artículos 128 a 142, Madrid, Cortes Generales/EDERSA, 1998, pág. 39: «las tendencias de los últimos años en favor del mercado, aparte de su carácter cíclico, no son, ni deberían pretender ser, resultado de una interpretación jurídica de la Constitución, sino el resultado de una preferencia económica o política en favor de la liberalización, que se mueve dentro del marco constitucional. Se trata por tanto de una opción política o ideológica y no del resultado de una interpretación constitucional que determine u obligue a orientar la economía hacia uno u otro escenario».

$10 R D$ 1673/2010, de 4 de diciembre (por el que se declara el primer estado de alarma en la democracia española para la normalización del servicio público esencial del transporte aéreo).

11 RD 1611/2010, de 3 de diciembre (por que se encomienda transitoriamente al Ministerio de Defensa las facultades de control de tránsito aéreo atribuidas a la entidad pública empresarial AENA).

12 Una síntesis de las posturas mantenidas en la doctrina en torno a la necesidad o no de reformar la Constitución española para adecuarla a las prescripciones del Tratado de Maastricht, en el ensayo de RALLO LOMBARTE, A.: «La prima riforma della Costituzione spagnola del 1978», Quaderni Costituzionali, n 3, 1993, así como, del mismo autor, el trabajo «El Tratado de Maastricht y el derecho de sufragio de los extranjeros en España», Revista de Derecho Político, no 36, 1992. 
flexibilidad constitucional (epígrafe III, infra) y, al tiempo, la cómoda postura doctrinal de reproche a un déficit democrático a escala europea que ahora se traslada acríticamente a nivel nacional (epígrafe IV, infra).

Con lo expuesto, no pretendo efectuar una mera crítica a quienes ostentan la legitimidad para la adopción de las decisiones sobre la reforma constitucional. Me dirijo asimismo, de manera autocrítica, a quienes tenemos como principal cometido no ser excesivamente circunspectos regocijándonos en la inercia de las categorías doctrinales cuales fruto de una dogmática constitucional expuesta sólo al asalto desde Europa. ¿Acaso no es más necesario el consenso para acometer reformas constitucionales como las cuatro propugnadas desde el Gobierno en la Legislatura 2004-2008 y que fueron objeto de mayor debate político y doctrinal a la luz del importante Informe del Consejo de Estado de 2006 sobre modificaciones de la Constitución española ${ }^{13}$ ? ¿U otras reformas constitucionales igualmente sugeridas ${ }^{14}$ ? ¿No percibimos un cierto agravio comparativo entre esas reformas (algunas de ellas de permanente discusión en el seno de las Cortes Generales, como la manida reforma del Senado) y la del artículo 135? (epígrafe V, infra).

\section{EL ECONOMICISMO TIMORATO COMO PRETEXTO PARA LA SUPERACIÓN DEL TABÚ DE LA REFORMA CONSTITUCIONAL}

En el presente epígrafe se pretende someter a debate que la reforma del artículo 135 $\mathrm{CE}$ ha respondido a una especie de economicismo timorato causado por nuestra pertenencia a la UE. Desde este punto de vista, considero que la reforma no era en modo alguno necesaria jurídicamente, sino más bien la consecuencia de un estado de necesidad económica y política provocado por una adicción a la irresponsabilidad en la toma de decisiones y de pusilanimidad académica en la actividad investigadora; lo que basaré en una doble argumentación: de un lado, la reforma del artículo 135 CE responde a una exigencia económica impuesta de modo fáctico a España como socio del club de los Veintisiete (y de los Diecisiete de la zona euro), y no como cabal imposición normativa del ordenamiento de la UE. Y, de otro lado, esa reforma comporta una inflexión en nuestro constitucionalismo histórico que no se encuentra justificada ni por la crisis económica y financiera actual ni por la reciente integración supranacional europea, pues el problema de fondo del equilibrio presupuestario y de la responsabilidad en el ámbito de la deuda pública es clásico.

13 Se trataba de la supresión de la preferencia del varón en la sucesión al trono, de la recepción en la Constitución del proceso de construcción europea, de la inclusión de la denominación de las Comunidades Autónomas y de la reforma del Senado. Léase ALVAREZ JUNCO, J., y RUBIO LLORENTE, F. (eds.): El informe del Consejo de Estado sobre la reforma constitucional. Texto del informe y debates académicos, Madrid, CEPC, 2006; así como, con anterioridad, las diversas contribuciones en la obra colectiva de TAJADURA TEJADA, J., y ROURA GÓMEZ, S. (coords.): La reforma constitucional. La organización territorial del Estado, la Unión Europea y la igualdad de género, Madrid, Biblioteca Nueva, 2005.

14 A título de ejemplo, JIMENA QUESADA, L.: «La necesaria reforma de la Carta Magna de 1978: requisito para la asunción de determinados compromisos constitucionales europeos», Nomos. Le attualità del diritto, $\mathrm{n}^{\circ} 3,2003$. 
Veamos el primer aspecto. Que la pertenencia a la UE radica esencialmente en la adhesión a parámetros de integración económica, con el leit motiv de las cuatro libertades económicas clásicas (libre circulación de capitales, mercancías, personas y servicios) y la política de competencia, es incuestionable ${ }^{15}$. Y la jurisprudencia del TJUE, tanto «clásica» como más reciente, ha venido perfilando dicha línea: en el lado clásico, baste mencionar la famosa sentencia Internationale Handelsgesellschaft Mbb (de 17 de diciembre de 1970 , asunto $11 / 70)^{16}$; por otro lado, la adopción de las más recientes Sentencias del TJUE Viking (de 11 de diciembre de 2007, asunto C-438/05) y Laval (de 18 de diciembre de 2007, asunto C-341/05) parece comportar que la dimensión social (concretamente, los derechos de sindicación y de negociación colectiva) habría quedado sometida a la lógica económica de los imperativos de la libre circulación y la libre concurrencia ${ }^{17}$, ilustrando una oposición «cuasicultural» ${ }^{18}$.

Que, por ello mismo, tanto en la superación de la fase práctica para la asunción progresiva del acervo comunitario antes del ingreso, como en la incorporación o transposición interna de las medidas normativas adoptadas en el seno de la Unión ya una vez como país miembro de ésta, la vertiente económica es prevalente. En estas coordenadas, el mayor impacto de la integración económica (que de la política o la social) conduce inexorablemente a que buena parte de la actividad legislativa de los Parlamentos (nacionales y, en su caso, regionales) de los Estados miembros de la UE consista en la adopción de leyes económicas tendentes a satisfacer las obligaciones comunitarias ${ }^{19}$.

Aclarado lo cual, con la excepción de la reforma constitucional española de 1992 (de corte político, relacionada — como se dijo- con el derecho de sufragio en las elecciones municipales como integrante de la noción de ciudadanía de la Unión introducida me-

15 Un exhaustivo análisis en PÉREZ DE LAS HERAS, B.: El mercado interior europeo. Las libertades económicas comunitarias: mercancías, personas, servicios y capitales, Bilbao, Universidad de Deusto, 2004.

16 En dicho pronunciamiento el Tribunal de Justicia ya avanzó (apartado 4) que la salvaguardia de los derechos fundamentales, «aunque se inspire en las tradiciones constitucionales comunes a los Estados miembros, debe ser garantizada en el marco de la estructura y de los objetivos de la Comunidad», siendo precisamente éstos de prevalente índole económica.

17 Analizando los asuntos Viking, Laval, Rüffert y Comisión contra Luxemburgo, ha criticado ASTOLA MADARIAGA, J.: «Lo social y lo económico en los Tratados de la Unión y en la jurisprudencia del Tribunal de Justicia», Revista Europea de Derechos Fundamentales, n 13, 2009, págs. 376-377: el poner frente a frente derechos económicos y derechos sociales «ha permitido saber la ponderación que de ellos hace el TJCE: los derechos sociales constituyen restricciones a los derechos económicos». Con igual espíritu crítico DEHOUSSE, F.: «Les arrêts Laval et Viking de la Cour de justice: vers une protection sociale plus petite dans une Europe plus grande?», Mélanges en hommage à Georges Vandersanden. Promenades au sein du droit européen, Bruxelles, Bruylant, 2008, en particular, págs. 500-502. Asimismo, RODIÈRE, P.: «L'impact des libertés économiques sur les droits sociaux dans la jurisprudence de la CJCE», Droit social, nº 5, 2010, pág. 578.

18 Así la califican MARGUÉNAUD, J.P., y MOULY, J.: «La jurisprudence sociale de la Cour EDH: bilan et perspectives», Droit social, N 9/10, 2010, pág. 891.

19 En lo que afecta a España, acúdase a JIMENA QUESADA, L.: «El impacto del Derecho europeo en la legislación española. Breve balance de veinte años de integración europea», Cuadernos de Integración Europea, $\mathrm{n}^{\circ}$ 4, marzo 2006, págs. 122-146: «desde el punto de vista cuantitativo, ha sido en el terreno del Derecho derivado (sobre todo, Directivas y Reglamentos comunitarios) y en cuestiones económicas en donde se ha hecho notar más ampliamente el impacto del Derecho de la Unión en el Derecho interno. (...) de manera más precisa en la incorporación de mandatos estrictamente financieros, prescripciones referentes al mundo de los servicios y la libertad de establecimiento, u obligaciones ligadas de manera transversal al "credo" de la Unión, es decir, la realización del mercado interior a través del respeto de las normas de competencia». 
diante el Tratado de Maastricht de 1992), los imperativos de integración económica de la UE nunca han producido, y ni siquiera planteado, la necesidad de una reforma de la Constitución española de 1978. Repárese en que ni la propia proyección de la Unión Económica y Monetaria impulsada asimismo desde el Tratado de Maastricht condujo a reformar nuestra Carta Magna, pese a ponerse en tela de juicio o, como mínimo dejar claramente obsoletas, algunas cláusulas constitucionales de ostensible impronta soberana, como la acuñación de moneda nacional que pasaba a ser remplazada por el euro ${ }^{20}$.

En consecuencia, la introducción del equilibrio presupuestario para respetar los compromisos de convergencia, estabilidad y crecimiento contraídos en el seno de la UE en modo alguno se revela preciso alcanzarlos a través de su inclusión en la Constitución nacional. En el caso de la reforma del artículo 135 CE, su Exposición de Motivos muestra una clara apuesta por la prioritaria integración económica, atemperada con una tímida y poco convincente apelación al Estado social ${ }^{21}$, que da pie para establecer un cierto paralelismo con el modo reticente y aislado con el que se introdujo mediante el Tratado de Lisboa el calificativo «social» en el modelo económico europeo, como «economía social de mercado» ${ }^{22}$. Si se trataba de hacer alardes de europeísmo social, los dos grandes partidos de la escena política española tenían la oportunidad de recuperar la asignatura pendiente que suspendieron mientras ocuparon el poder, esto es, ratificando la versión moderna del Pacto europeo de democracia social por excelencia (la Carta Social Europea revisada de 1996 del Consejo de Europa, que por cierto sirvió de modelo para la elaboración del catálogo de derechos sociales de la Carta de Derechos Fundamentales de la $U E)^{23}$. Por añadidura, se llega a sostener en la citada Exposición de Motivos que la estabilidad presupuestaria constituye «un valor, pues, que justifica su consagración consti-

20 Sobre este punto, afirmó DE ESTEBAN, J.: «La Constitución irreformable», El Mundo, 4 de marzo de 2002, pág. 5: «no hay ningún artículo en nuestra Norma Fundamental que se refiera específicamente a Europa, cuando gran parte de las competencias que se atribuyen en ella al Estado, ya han sido transferidas a las instituciones europeas. Por poner un ejemplo significativo baste citar que, según el artículo 149.1.11, es competencia exclusiva del Estado todo lo referente al sistema monetario (divisas, cambio y convertibilidad) y, sin embargo, ya no hay una moneda española, sino europea, cuya regulación depende del Banco Europeo».

21 Se lee en la Exposición de Motivos: «Más de treinta años después de la entrada en vigor de la Constitución, formando parte España de la Unión Económica y Monetaria Europea, que consolida y proyecta sus competencias en el marco de una creciente gobernanza común, y siendo cada vez más evidentes las repercusiones de la globalización económica y financiera, la estabilidad presupuestaria adquiere un valor verdaderamente estructural y condicionante de la capacidad de actuación del Estado, del mantenimiento y desarrollo del Estado Social que proclama el artículo 1.1 de la propia Ley Fundamental y, en definitiva, de la prosperidad presente y futura de los ciudadanos».

22 En concreto, se cita dicha fórmula en el artículo 3.3 TUE, con la adjetivación de «social» («economía social de mercado altamente competitiva») por vez primera en el Derecho originario. Ahora bien, semejante adjetivación aparece aislada en dicha disposición del TUE y desaparece por completo cuando incluso el TFUE se remite al propio art. 3.3 TUE: es el caso del artículo 119 TFUE (anterior artículo 4 TCE), que alude al «principio de economía de mercado abierta y de libre competencia» (y, en igual sentido, los artículos 120 y 127 TFUE).

23 Según las Explicaciones anejas, hasta siete derechos fundamentales de la Carta de la Unión se inspiran en otros tantos de la Carta Social Europea revisada de 1996 (CSEr): el artículo 23 sobre igualdad entre mujeres y hombres (se inspira en el artículo 20 CSEr), el artículo 25 sobre derechos de las personas mayores (en el artículo 23 CSEr), el artículo 27 sobre derecho a la información y consulta de los trabajadores en la empresa (en el artículo 21 CSEr), el artículo 30 sobre protección en caso de despido injustificado (en el artículo 24 CSEr), el artículo 31 sobre condiciones de trabajo justas y equitativas (en el artículo 26 CSEr), el artículo 33 sobre vida familiar y vida profesional (en el artículo 27 CSEr), y el artículo 34 sobre seguridad social y ayuda social (en los artículos 30 y 31 CSEr). 
tucional, con el efecto de limitar y orientar, con el mayor rango normativo, la actuación de los poderes públicos».

Al hilo de esto último (el verbo «orientar» parece más bien rememorar un carácter programático de las normas constitucionales afortunadamente superado por su contemporáneo valor normativo), tengo la impresión de que en España no se ha reflexionado sobre si, al dotar de rango constitucional explícito al equilibrio presupuestario, se está facilitando realmente su garantía jurídica en la praxis en el terreno interno. Tampoco estoy seguro de que en Alemania (país que, a través de su Canciller Angela Merkel y por ya consignarla en su Ley Fundamental ${ }^{24}$, lanzó esa exigencia de constitucionalización interna) se haya calculado el impacto práctico de esa constitucionalización, que posiblemente sea germen de mayores divergencias entre los Tribunales Constitucionales y el Tribunal de Justicia de la Unión Europea ${ }^{25}$; a menos que ese posible debilitamiento de la jurisdicción de Luxemburgo y correlativo fortalecimiento de las jurisdicciones constitucionales, sea un objetivo oculto de esa propuesta alemana (conocida es la posición del Tribunal Constitucional Federal alemán en materia de construcción europea, ilustrada asimismo mediante su última sentencia relativa al Tratado de Lisboa ${ }^{26}$ ). En el caso del TC

24 CORDERO GONZÁLEZ, E.: «La reforma de la Constitución financiera alemana. En particular, el nuevo límite al endeudamiento de la Federación y los Länder», TRC, n 29, 2012, pág. 289 y ss.

25 Ibidem: para la citada autora, tras recordar que la reforma del artículo 135 CE se inspira en los artículos 109 y 115 de la Ley Fundamental de Bonn y contrastar la rápida y coyuntural puesta en práctica del procedimiento de reforma en España en comparación con un proceso más amplio de revisión del federalismo alemán que condujo a la reforma germana de 2009 (p. 289-290), resulta dudosa la conveniencia de constitucionalizar el principio de estabilidad presupuestaria en España por la dificultad de articular un efectivo control de constitucionalidad sobre el cumplimiento de los límites impuestos. Así, «en nuestro ordenamiento, por otra parte, el problema de la adecuación de las limitaciones al endeudamiento autonómico a la autonomía financiera de las Comunidades Autónomas no se plantea con motivo de la introducción del citado límite en la Constitución, al no existir en ella la protección reforzada existente en Alemania para el principio federal, que permite enjuiciar la constitucionalidad de las modificaciones introducidas en la propia Constitución. La adecuación de la legislación en materia de estabilidad presupuestaria a la autonomía financiera de las Comunidades Autónomas ha sido afirmada, por otra parte, por diversas sentencias del TC español, entre las que destaca la 134/2011, de 20 de julio. En ella se avala la constitucionalidad de las medidas de control estatal sobre los presupuestos autonómicos con fundamento en la competencia del Estado sobre la dirección de la actividad económica general, establecida en el art. 149.1.13 de la Constitución y en el principio de coordinación con la Hacienda estatal, recogido en el art. 156.1, como condicionante de la autonomía financiera de las Comunidades Autónomas. Ya con anterioridad, la Ley Orgánica de Financiación de las Comunidades Autónomas exigía la autorización estatal para la contracción de ciertas operaciones de crédito por parte de las Comunidades Autónomas, que también había sido avalada por el Tribunal Constitucional con idéntico fundamento [entre otras SSTC 179/1987, de 12 de noviembre, y 87/1993, de 11 de marzo]. El debate existente en Alemania, a este respecto, puede considerarse, por ello, resuelto en nuestro país a la luz de la doctrina reciente del Tribunal Constitucional». Cabría añadir que la jurisprudencia constitucional española reciente en materia de estabilidad presupuestaria, además de la citada STC 134/2011, se ha visto consolidada (con la desestimación de los correspondientes recursos) mediante otras posteriores, como la STC 157/2011, de 18 de octubre de 2011; las SSTC 185, 186, 187, 188 y 189/2011, de fecha 23 de noviembre de 2011; las SSTC 195, 196, 197, 198, 199/2011, todas ellas de 13 de diciembre de 2011, así como la STC 203/2011, de 14 de diciembre de 2011.

26 Se trata de la Sentencia de la Sala Segunda del Tribunal Constitucional Federal alemán de 30 de junio de 2009 que avala la constitucionalidad, en general, del Tratado de Lisboa. Lo más importante radica en que la jurisdicción constitucional germana da luz verde a la última gran reforma de los Tratados europeos, sin perjuicio de no abdicar de su posición para supervisar la afectación al orden constitucional alemán del proceso de integración europea y sin descartar la posible adopción futura de pronunciamientos como el ya adoptado con relación 
español, la doctrina ha criticado sus problemas de aprehensión con respecto a la integración europea $^{27}$, pese a algún atisbo reciente de voluntad jurisdiccional convergente ${ }^{28}$.

Acometamos ahora el segundo elemento. A este respecto, antes de su reforma, se había comentado que el artículo $135 \mathrm{CE}$ «ha estado presente, con ciertas diferencias, es cierto, en todos los textos constitucionales españoles desde el primero, la Constitución de Cádiz de 1812», así como que «su fundamento se encuentra en la capacidad que el Estado tiene para generar confianza en los prestamistas; en su solvencia económica, en definitiva» ${ }^{29}$. Esto es, «que el Estado, al emitir Deuda pública, compromete su capacidad de confianza y su solvencia», resultando incluso «mucho más ilustrativos y más claros los textos constitucionales del siglo XIX que, con expresiones prácticamente idénticas, aludían a los ingresos obtenidos "sobre el crédito de la Nación" ${ }^{30}$.

En suma, el artículo 135 sería un precepto «clásico» en las Constituciones españolas. Y seguramente no fuera necesario enmendarlo ${ }^{31}$. Cabalmente, el debate constituyente sobre la reforma del artículo 135 puso de manifiesto que el desarrollo legislativo en materia de estabilidad presupuestaria ha estado en la agenda de los dos partidos mayoritarios proponentes cuando han ocupado el poder $^{32}$; y la Ley Orgánica cuya adopción manda el nue-

a la euroorden (Sentencia de 18 de julio de 2005, que declaró la nulidad de la Ley alemana de 21 de julio de 2004 que incorporaba la euroorden por cuanto, en esencia, dicha ley no preveía la negativa a entregar a la persona reclamada cuando el delito se hubiera cometido en Alemania ni permitía interponer un recurso contra la decisión de entrega): sostiene en tal dirección en el apartado 337 de la Sentencia de 30 de junio de 2009 que «confiando en el Tribunal de Justicia de las Comunidades Europeas», para llevar a cabo el análisis de que la ejecución del Derecho de la UE en Alemania no va contra el «estándar de los derechos fundamentales en la Constitución alemana, (...) el Tribunal Constitucional Federal puede, sin embargo, reconocer el carácter final de las decisiones del Tribunal de Justicia sólo en principio» [BVerfG, 2 BvE 2/08 vom 30.6.2009, Absatz-Nr. (1-421)].

27 Acúdase a la obra de TAJADURA TEJADA, J., y DE MIGUEL BÁRCENA, J.: Justicia Constitucional y Unión Europea, Madrid, CEPC, 2008. En el Prólogo a dicha obra, A. TORRES DEL MORAL advierte que la cuestión más importante desde el punto de vista jurídico radica en las relaciones del ordenamiento jurídico comunitario con los ordenamientos creados por los Estados miembros, «y en esto la polémica no ha cesado, ni cesará, viéndose los especialistas envueltos en disquisiciones sobre la primacía del Derecho comunitario y la supremacía de las Constituciones nacionales» (p. XII); y en el contexto de dicha advertencia critica cómo el propio TC español ha mostrado «terquedad» en «no enfrentarse directamente con el problema de las relaciones entre los dos Ordenamientos cuando ello pueda afectar, de un modo u otro, a la Constitución española, lo que sucede con más frecuencia de la que él quiere convencerse y convencernos» (p. XVI).

28 En tal dirección, la primera cuestión prejudicial planteada por nuestro guardián de la Constitución al TJUE, mediante Auto 86/2001, de 9 de junio, en el marco de un recurso de amparo que trae su causa de la entrega de un ciudadano italiano acordada por la Audiencia Nacional con respecto a la ejecución de una «euroorden» para el cumplimiento de una condena penal impuesta en rebeldía por un delito de quiebra fraudulenta.

29 TEJERIZO LÓPEZ, M.: «Artículo 135: Deuda pública», en Comentarios a la Constitución española de 1978 (dir. O. ALZAGA VILlAAMIL), tomo X, Artículos 128 a 142, Madrid, Cortes Generales/EDERSA, 1998, pág. 347.

30 Ibídem, pág. 348.

31 Con tal orientación, SULKOWSKI, J. y LABNO, A.: «Protección del equilibrio presupuestario en la Constitución de Polonia», TRC, n 29, 2012, pág. 355-356: dichos autores, tras subrayar que «la crisis financiera actual demuestra la importancia de la función estabilizadora y garantizadora de los textos constitucionales; de tal suerte, en la época del endeudamiento sustancial de los países, resulta necesario utilizar mecanismos que equilibren los importes de los ingresos y gastos estatales», concluyen no obstante que «el papel del Derecho constitucional y de sus representantes no consiste evidentemente en poner solución a los dilemas económicos».

32 Queda ilustrada tal circunstancia en el propio debate parlamentario sobre la reforma constitucional, por ejemplo en la sesión de 6 de septiembre de 2011 de la Comisión constitucional del Senado (Diario de Sesiones, 
vo artículo 135 dentro de un plazo perentorio (Ley Orgánica 2/2012, de 27 de abril, de Estabilidad Presupuestaria y Sostenibilidad Financiera) se inscribe en esa línea. Sin embargo, se ha dado la paradoja de haber sido aprobada sin el mismo grado de consenso que la reforma constitucional, al oponerse en esta ocasión ambos partidos mayoritarios ${ }^{33}$, generando así la contienda política la extraña sensación en la ciudadanía de que quien puede pactar lo más no es capaz en cambio de ponerse de acuerdo en lo menos. A mayor abundamiento, la flexibilidad con la que se ha interpretado el principio de reserva de ley en materia de deuda pública (hasta el punto de avalarse la emisión de ésta utilizando el vehículo del Decreto-Ley) en función de las exigencias de los mercados, convierte en más extraña si cabe la formalización detallada de los límites máximos de endeudamiento en el Texto constitucional ${ }^{34}$.

Así pues, por paradójico que parezca, el tabú de la reforma constitucional ha sido superado merced a ese economicismo timorato que, cual poder fáctico ejerciente desde el exterior (UE) y desde el interior (Comunidades Autónomas), ha conducido a una innecesaria y compleja regulación constitucional que era suficiente con su redacción clásica. En síntesis, puede decirse que el nuevo texto del artículo 135 no añade nada a la Ley Orgánica 2/2012 o a la legislación anterior en la materia ${ }^{35}$, más allá de un trasfondo simbólico (con el precio de la reforma constitucional) en el que el Estado español ha sobreactuado con respecto al poder de Europa y con relación al poder de las Comunidades Autónomas $^{36}$. En ese difícil equilibrio de poderes a la sombra del nuevo artículo $135 \mathrm{CE}$,

Senado, IX Legislatura, no 561); el Sr. Pérez Sáenz (PSOE) sostenía: «Todos los grupos que hoy ponen matices de fondo al equilibrio presupuestario votaron en esta Cámara en el año 2006 una ley que contenía ese principio. Fue un principio adoptado por todos, y lo que hacemos hoy es elevarlo de rango y pasarlo de una ley orgánica a la Constitución española» (p. 5); por su lado, la Sra. Rodríguez Herrer (PP) afirmaba con matices (p. 6): «Soy interventora de Hacienda y era la secretaria de Estado de Presupuestos cuando se redactaron y aprobaron las leyes de estabilidad presupuestaria y la reforma de la Ley General Presupuestaria que las incluía, y además fui la portavoz de mi grupo parlamentario en el Congreso de los Diputados en la primera reforma de las leyes de estabilidad, allá por el año 2005 y comienzos de 2006, defendiendo precisamente nuestra posición contraria a una reforma que relajó la disciplina presupuestaria, especialmente desde su concepción global o estatal».

33 De hecho, en el Congreso de los Diputados, la Ley Orgánica 2/2012 salió adelante por 192 votos a favor (PP, al que se sumaron CiU, UPyD y UPN), 116 en contra (PSOE y resto de grupos de la Cámara baja) y 4 abstenciones (con PNV).

34 Véase TEJERIZO LÓPEZ, M.: «Artículo 135: Deuda pública», ya cit., pág. 359 y pág. 364: se refiere dicho autor a los «límites máximos de endeudamiento, límites que, además, deben ser adoptados con la flexibilidad que demande el mercado de capitales de cada momento. Soy consciente de que, con esto, la reserva de ley en materia de Deuda pública prácticamente no existe. Pero, me parece, que éste es el signo de los tiempos contra el que poco pueden hacer pruritos de corte exclusivamente formalista», por lo que debería seguir incidiéndose en la «responsabilidad económica del Tesoro».

35 Parece evocar tal lectura MEDINA GUERRERO, M.: «La reforma del artículo 135 de la Constitución», TRC, n 29, 2012, pág. 132: «La Constitución material sobre esta materia estará también integrada por la Ley Orgánica anunciada en el nuevo artículo 135 CE».

36 A título de ejemplo, formuló en nombre de CiU el Sr. Durán i Lleida la siguiente crítica en el debate parlamentario sobre la reforma: «Modificar la Constitución requiere seriedad. Claro que se debe limitar el déficit estructural, pero para ello hay que plantearse si es o no necesario una sustitución o un cambio constitucional. Para nosotros lo que se requiere es una actuación legislativa y ejecutiva ordinaria adecuada a los ingresos. Durante estos tiempos pasados hemos echado la casa por la ventana — que es lo que se ha hecho durante los últimos años- y ahora se ven obligados a sobreactuar ante los mercados para impedir a corto plazo nuevas crisis financieras. (...) Limitar la autonomía financiera de las comunidades autónomas al incrementar el rango legal del principio de estabilidad presupuestaria va en contra del actual reconocimiento de autonomía financiera de la Constitución española» (DSCD, IX Legislatura, 30 de agosto de 2011, n² 269, pág. 8) 
al lado de la Ley Orgánica 2/2012 encontramos los dos recientes y controvertidos Tratados europeos en la materia (el Tratado Constitutivo del Mecanismo Europeo de Estabilidad hecho en Bruselas el 2 de febrero de 2012, y el Tratado de Estabilidad, Coordinación y Gobernanza en la Unión Económica y Monetaria firmado en Bruselas el 2 de marzo de 2012) ${ }^{37}$, así como algunas Leyes autonómicas en ese mismo ámbito (verbigracia, la Ley catalana 6/2012, de 17 de mayo, de estabilidad presupuestaria, o la Ley 5/2012, de 7 de junio, de estabilidad presupuestaria de Aragón).

A decir verdad, el aparente éxito de la consensuada reforma «exprés» del artículo $135 \mathrm{CE}$ esconde el fracaso de las insuperables asimetrías a escala europea y a nivel territorial interno. Esas asimetrías son lógicamente germen de desigualdades y de inseguridad jurídica. Con relación a este segundo aspecto de la ausencia de certeza legal repárese en que, además de esos dos Tratados europeos, el ordenamiento de la UE no únicamente se ve completado por una ingente legislación derivada o secundaria, sino asimismo por modificaciones del Derecho primario u originario de bajo perfil en clave de legitimidad democrática como, por ejemplo, la Decisión del Consejo Europeo de 25 de marzo de 2011 que modifica el artículo 136 del Tratado de Funcionamiento de la Unión Europea en relación con un mecanismo de estabilidad para los Estados miembros cuya moneda es el euro ${ }^{38}$; y, en el terreno interno, disposiciones como la Ley de Economía Sostenible (Ley 2/2011 de 4 de marzo) no constituyen precisamente un instrumento loable en términos de técnica legislativa ni han quedado a salvo de recursos ${ }^{39}$.

Para completar el presente epígrafe cabe incidir en que la legislación española económica es ingente, incluso la tendente a evitar problemas de equilibrio presupuestario: buen ejemplo lo ofrece la Ley 15/2010, de 5 de julio, de modificación de la Ley 3/2004, de 29 de diciembre, por lo que se establecen medidas de lucha contra la morosidad en las operaciones comerciales $^{40}$. Ahora bien, esa legislación se ha revelado incapaz de atajar los problemas

37 Ambos habrían asestado a la ciudadanía un duro golpe («de Estado europeo»), según JENNAR, R.M.: «Deux traités pour un coup d'État européen», Le Monde Diplomatique, nº 699, junio 2012, pág. 12-13.

38 Decisión adoptada en virtud del artículo 48.6 TUE, publicada en el Diario Oficial de la Unión Europea, L 91, de 6 de abril de 2011.

39 Desde el punto de vista de la técnica legislativa, la Ley 2/2011 de Economía Sostenible es un texto denso que, precedido por un índice, se integra por un Preámbulo, ciento catorce artículos, veinte disposiciones adicionales, nueve disposiciones transitorias, una disposición derogatoria, sesenta disposiciones finales y un anexo a la disposición adicional sexta; además, en su complejidad técnica, ha contado con ulteriores desarrollos como la Ley Orgánica 4/2011, de 11 de marzo, complementaria de la Ley de Economía Sostenible, por la que se modifican las Leyes Orgánicas 5/2002, de 19 de junio, de las Cualificaciones y de la Formación Profesional, 2/2006, de 3 de mayo, de Educación, y 6/1985, de 1 de julio, del Poder Judicial. Por el momento, se han admitido a trámite por el Pleno del TC tres recursos de inconstitucionalidad: el n ${ }^{\circ}$ 6596-2011 (promovido por el Gobierno de la Generalitat de Cataluña), contra los artículos 101, apartados $1,2,3$ y 4; 102; 110, apartado 4; 111, apartado 6, y disposición final primera, apartado 1, párrafos primero y último, y apartado 2.b) de la Ley 2/2011, de 4 de marzo, de Economía Sostenible (admitido mediante providencia de 20 de diciembre de 2011; BOE n 313 de 29 de diciembre de 2011); el n 6642-2011 (promovido por el Gobierno de Canarias), contra los artículos 4 a 7, 41.uno, 80, 91 y 110.4 de la Ley 2/2011 (admitido asimismo mediante providencia de 20 de diciembre de 2011; mismo BOE ${ }^{\circ}$ 313 de 29 de diciembre de 2011); y el n 2703-2011 (promovido por el Parlamento de Canarias) contra la disposición transitoria octava y las disposiciones finales vigesimoséptima, vigesimoctava y trigésima de la Ley 2/2011 (admitido mediante providencia de 7 de junio de 2012, BOE n 143 de 16 de junio de 2011).

40 En el Preámbulo de la Ley 15/2010 se señala que «los efectos de la crisis económica se han traducido en un aumento de impagos, retrasos y prórrogas en la liquidación de facturas vencidas, que está afectando a todos los sectores. En especial, está afectando a las pequeñas y medianas empresas, que funcionan con gran depen- 
de tesorería de las entidades públicas que, a su vez, han acarreado consecuencias nefastas para las empresas privadas y, por ende, para el mercado laboral y el conjunto del modelo productivo. En definitiva, se ha introducido una innecesaria nueva cláusula constitucional cuya finalidad bien podía satisfacerse a través de una disposición legislativa (si se quiere, la propia Ley Orgánica 2/2012, de 27 de abril, de Estabilidad Presupuestaria y Sostenibilidad Financiera), puesto que el problema de fondo ha residido en una práctica ausencia de articulación de mecanismos de exigencia de responsabilidad de los agentes políticos, económicos y financieros implicados. Y cualquier pretexto en este terreno se torna peregrino, desde el momento en que la factibilidad general de las leyes implica el análisis de su impacto económico a priori y la verificación a posteriori ${ }^{41}$.

\section{EL EUROPEÍSMO CONVENIENTE COMO CAUSA DE LA FLEXIBILIDAD DEL PROCEDIMIENTO DE REFORMA CONSTITUCIONAL}

Si ponemos nuevamente la mirada en la Exposición de Motivos de la reforma del artículo $135 \mathrm{CE}$, comprobamos que dicha enmienda no responde a una necesidad de adecuarse a exigencia normativa europea concreta alguna, sino más sencillamente a la «conveniencia de llevar el principio de referencia [de estabilidad presupuestaria] a nuestra Constitución, al objeto de fortalecer la confianza en la estabilidad de la economía española a medio y largo plazo. La presente reforma del artículo 135 CE persigue, por tanto, garantizar el principio de estabilidad presupuestaria, vinculando a todas las Administraciones Públicas en su consecución, reforzar el compromiso de España con la Unión Europea y, al mismo tiempo, garantizar la sostenibilidad económica y social de nuestro país».

Por consiguiente, ese europeísmo conveniente se ha erigido en la natural causa de una fácil reforma de la Carta Magna española; un complejo europeísmo que, a todas luces, ha dejado en agua de borrajas la aparentemente sólida teoría del procedimiento especial de reforma como causa de la rigidez constitucional. Sobre esta cuestión, me parece que se confirma la percepción de Pace quien ${ }^{42}$, confrontando el pensamiento de

dencia al crédito a corto plazo y con unas limitaciones de tesorería que hacen especialmente complicada su actividad en el contexto económico actual». A tal efecto, desde el punto de vista de los plazos de pago del sector público, se reduce a un máximo de treinta días el plazo de pago, que se aplicará a partir del 1 de enero de 2013, siguiendo un período transitorio para su entrada en vigor. En lo que se refiere a los plazos de pago entre empresas, se establece un plazo máximo de pago de 60 días por parte de empresas para los pagos a proveedores. Este plazo de pago no podrá ser ampliado por acuerdo entre las partes, con el fin de evitar posibles prácticas abusivas de grandes empresas sobre pequeños proveedores, que den lugar a aumentos injustificados del plazo de pago. A este efecto se establece un calendario transitorio que culminará el 1 de enero de 2013.

41 En este ámbito, RAVERAIRA, M.: «Applicazione e fattibilità legislativa», en Applicazione e tecnica legislativa (coords. E. PATTARO y F. ZANNOTTI), Milano, Giuffrè, 1998; así como MONTORO CHINER, M.J.: Adecuación al ordenamiento y factibilidad: presupuestos de calidad de las normas, Madrid, CEC, 1989.

42 Entre las contribuciones de Alessandro PACE, pueden leerse sus libros La causa della rigidità costituzionale, Padova, Cedam, 1996; Potere costituente, rigidità costituzionale, autovincoli legislativi, Padova, Cedam, 1997; y sus ensayos «La "naturale" rigidità delle costituzioni scritte», Giurisprudenza Costituzionale, 1993, pág. 4085 ss. (trad. esp. «La "natural” rigidez de las constituciones escritas», en PACE, A., y VARELA, J.: La rigidez de las constituciones escritas, Madrid, CEC, 1995, pág. 11 ss.); «In difesa della "naturale" rigidità delle costituzioni 
Dicey ${ }^{43}$ con el de Bryce ${ }^{44}$, se alinea con el segundo para concluir que la modificación mediante un procedimiento especial de reforma «no es, por ello mismo, para Bryce, a diferencia de Dicey, esencial para el concepto de constitución rígida. Para Bryce, la previsión de una posibilidad de modificación es, efectivamente, sólo eventual» ${ }^{45}$.

Con tal premisa, puede sostenerse que la reforma del artículo 135 CE no se sustrae a la conciencia que ya a finales del siglo XVIII se difundía acerca de la triple función llevada a cabo por el procedimiento especial de reforma constitucional, a saber: primeramente, se evitaría la fragilidad política derivada de la absoluta inmodificabilidad o petrificación de las normas constitucionales (los dos grandes partidos, aun a costa de excluir del consenso a los demás del arco parlamentario español, habrían pretendido con la modificación constitucional mostrar mediante esa unidad coyuntural de fuerzas una aparente solidez para asegurar el rumbo político de España); en segundo lugar, no se dejaría de garantizar la relativa estabilidad de las reglas de la constitución escrita (justamente por cuanto ni PSOE ni PP habrían podido sacar adelante unilateralmente esa reforma constitucional, ni siquiera la menos cualificada prevista en el artículo $167 \mathrm{CE}$ ); y, en fin, se habría dado cauce de tal suerte al principio según el cual cada generación debe estar en condiciones de afrontar todas las decisiones que requieran las circunstancias de su tiempo (el afrontar la grave crisis actual en clave de modelo económico-cultural europeo habría servido como una coartada inapelable para que los dos grandes partidos acometan la reforma del artículo $135 \mathrm{CE})^{46}$.

En este orden de consideraciones, se verifica que la rigidez es sólo un atributivo de la Constitución escrita, la cual, formalmente, se sitúa como superior y, sustancialmente, viene legitimada por el consenso popular en virtud de su contenido o bien de otros factores concomitantes de orden subjetivo y/o político. Con ello, siguiendo nuevamente a Pace, queda demostrado lo importantes que son, en el Derecho Constitucional y en la Política, los condicionamientos culturales ${ }^{47}$ y como éstos, por lo demás, propician la

scritte», Giurisprudenza costituzionale, 1995, pág. 1209 ss. (trad. esp. «En defensa de la "natural” rigidez de las constituciones escritas», en PACE, A., y VARELA, J.: La rigidez de las constituciones escritas, cit., pág. 115 ss.); «L'instaurazione di una nuova costituzione. Profili di teoria costituzionale», Quaderni costituzionali, 1997, pág. 7 ss.; «Presentazione» de la monografía de BRYCE, J.: Costituzioni flessibili e rigide (Flexible and Rigid Constitutions, 1901), trad. it. R. Niro, Milano, Giuffrè, 1998; o «Morte di una Costituzione», Giurisprudenza Costituzionale, 1999, pág. 1544 ss. (trad. esp. «Muerte de una constitución», Revista Española de Derecho Constitucional, $\mathrm{n}^{\circ} 57,1999$, pág. 271 ss.).

43 DICEY, A.V.: Introduction to the Study of the Law of the Constitution, London, Macmillan, 1885.

44 BRYCE, J.: «Flexible and Rigid Constitutions», en Studies in History and Jurisprudence, vol. I, Clarendon Press, Oxford, 1901.

45 PACE, A.: «Constituciones rígidas y constituciones flexibles», Cuadernos Constitucionales de la Cátedra Fadrique Furió Ceriol, n 33, 2000, pág. 24: Y prosigue: «Que sea ésta, y no la referida por Dicey, la tesis sostenida por Bryce queda, por lo demás, comprobado por el hecho de que — según Bryce- pertenecieran a este segundo tipo de constitución ya sea las Chartes constitutionnelles francesas de 1814 y de 1830, ya sea el Estatuto Albertino de 1848: todas éstas cartas constitucionales que, como es conocido, no preveían procedimientos de reforma» (p. 25).

46 Para afrontar la traslación de esa triple función del procedimiento especial de reforma constitucional a la modificación del artículo 135 CE he tenido presentes las consideraciones de Emmanuel Siéyès y de Thomas Paine, tal como son expuestas por PACE, A.: «La instauración de una nueva constitución. Perfiles de teoría constitucional», REP, $\mathrm{n}^{\circ} 97,1997$, págs. 9 ss.

47 PACE, A.: «Constituciones rígidas y constituciones flexibles», ya cit., pág. 36. El citado autor trae a colación, para incidir en los condicionantes culturales, la tesis recurrentemente sostenida por HÄBERLE, P.: «I 
transformación en flexible de una constitución que, siendo escrita, es «naturalmente», pero no «esencialmente», rígida. En estas condiciones, «el estudio de la rigidez constitucional conserva, a mi entender, toda su actualidad y relevancia teórica», de tal suerte que «el estudio de la rigidez constitucional nos coloca, brutalmente, frente a la ambigüedad de una ley, que pese a ser "escrita" y "superior", padece la arrolladora prevalencia de la opinión pública y no se encuentra en condiciones de resistir frente a la subrepticia fuerza subversiva de la praxis y de la costumbre» ${ }^{48}$.

Así pues, el episodio de la reforma del artículo 135 CE ha probado la práctica inocuidad del procedimiento de reforma como causa de la rigidez o la flexibilidad del Texto constitucional, más bien expuesto a los avatares del factor económico-cultural europeo y de la voluntad política, que han arrastrado por su corriente a la doctrina constitucionalista mayoritaria hasta casi hacerla naufragar ${ }^{49}$. Podría sostenerse, no sin cierto cinismo, que este episodio constituiría la excepción a la regla general. El tiempo lo dirá; pero el europeísmo, correctamente entendido, no debe percibirse como un ataque a las categorías del Derecho constitucional; la europeización tiene que impregnar y verse como parte integrante del Derecho constitucional. En otro caso, la idea de «Derecho constitucional europeo» sólo será un cínico pretexto para aproximarse a la integración europea con cierto complejo y discutible solvencia.

Obviamente, las mayorías cualificadas requeridas para la reforma persiguen dotar de legitimidad y consenso a los cambios del Texto constitucional; pero procedimiento de reforma y rigidez de la Constitución no constituyen en absoluto una ecuación indiscutible; o, dicho con otras palabras, el procedimiento especial de reforma tendría una función garantista, pero no se erigiría en la causa de la rigidez constitucional, que entroncaría más bien con la existencia del reiterado consenso ${ }^{50}$. El asociar procedimiento de reforma a la

diritti fondamentali nelle società pluraliste e la costituzione del pluralismo», en La democrazia di fine secolo (a cargo de M. LUCIANI), Bari, Laterza, 1994, así como en Verfassungslehre als Kulturwissenschaft, Berlín, Duncker \& Humboldt, 1998.

48 PACE, A.: «Constituciones rígidas y constituciones flexibles», ya cit., pág. 37. En esta línea, ya observaron DE ESTEBAN, J., y GONZÁLEZ-TREVIJANO, P. J.: Curso de Derecho Constitucional Español, vol. III, Madrid, Universidad Complutense, $1^{\text {a }}$ ed., 1994, pág. 712: «las Constituciones que más perduran son aquéllas que, aunque fijen un procedimiento agravado de revisión, permiten en la práctica su reforma». Léase asimismo GARCÍA-ATANCE, M.V.: «Perfil ambivalente de la fórmula de reforma constitucional», Revista de Derecho Político, no $31,1990$.

49 Resulta pertinente acudir a la crítica formulada por RUIPÉREZ, J.: «Una cuestión nuclear para la Teoría del Derecho constitucional: sobre la reforma de la Constitución y sus funciones en el Estado constitucional democrático», Anuario da Facultade de Dereito da Universidade da Coruña, 1997, pág. 496: según dicho autor, poco importa que el Código Fundamental haya establecido un sistema especial para su propia modificación formal cuando se pretenden hacer prevalecer unos intereses políticos concretos y coyunturales sobre los intereses constitucionales. Con respecto al concreto debate doctrinal generado por la reforma del artículo 135 CE, además del ya citado monográfico sobre La reforma constitucional de TRC, $\mathrm{n}^{\circ} 29,1^{\circ}$ semestre 2012, puede acudirse a la encuesta sobre La reforma del artículo 135 CE publicada en Revista Española de Derecho Constitucional, no 93, 2011; así como a las diversas contribuciones que aparecen en la obra de ÁLVAREZ CONDE, E. y SOUTO GALVÁN, C. (coords.): La constitucionalización de la estabilidad presupuestaria, Madrid, Universidad Rey Juan Carlos, Madrid, 2012.

50 Con semejante espíritu, ROURA GÓMEZ, S.: «Los procedimientos de reforma en las experiencias del constitucionalismo republicano español (1873 y 1931)», REP, $\mathrm{n}^{\circ} 101$, 1998, pág. 300-301; y de este mismo autor, acúdase a su más extensa monografía La defensa de la Constitución en la Historia Constitucional española. Rigidez y control de constitucionalidad en el constitucionalismo histórico español, Madrid, CEPC, 1998. 
catalogación de la Constitución como rígida o flexible puede configurarse como un instrumento pedagógico interesante, si bien aclarando que la realidad es mucho más compleja, sobre todo en clave de integración europea. De igual manera, el seguir aferrados a una teoría de los derechos fundamentales asociada particularmente a la garantía del recurso de amparo constitucional supone desconocer la realidad de la europeización del canon constitucional de defensa de los derechos y libertades ${ }^{51}$; y, en este caso, la citada teoría ni siquiera sería pedagógica, por ignorar la relación de las normas constitucionales con la realidad y el sistema normativo europeo en los que son aplicadas ${ }^{52}$.

Colocados en la tesitura de atisbar un balance positivo de la reforma del artículo 135 CE cabría apuntar su potencialidad para acometer otras reformas que, éstas sí, serían necesarias o más convenientes, sin perder de vista la perspectiva europea. En concreto, entre las más acordes con la actual realidad nacional e internacional, el tiempo ha demostrado el carácter insuficiente de la reforma del artículo 13.2 CE operada en 1992, puesto que la condición de reciprocidad impuesta por dicha disposición (no suprimida en esa primera reforma constitucional) entorpece enormemente la posible extensión del derecho de sufragio pasivo en elecciones municipales a todas las personas extranjeras. El debate se ha vuelto a reabrir recientemente en países como Francia en el contexto de la campaña electoral presidencial que ha conducido a François Hollande a la Jefatura del Estado ${ }^{53}$. Y, en España, constituye un aspecto de los derechos de participación política que hasta el presente ha ido más bien de la mano de la comparación del arraigo de las personas extranjeras en España con las raíces de la ciudadanía española en el exterior ${ }^{54}$. Diversamente, no hace falta siquiera acudir a dicha comparación, pues contamos con cánones europeos que nos están indicando el carácter problemático de la cláusula de reciprocidad del artículo 13.2 CE, particularmente la Convención del Consejo de Europa relativa a la participación de los extranjeros en la vida pública a nivel local de 5 de febrero de 1992 (sintomático es que España no sólo no la ha ratificado, sino ni siquiera firmado).

Por su parte, entre las reformas más convenientes que la del artículo 135 CE cabría situar, si acaso, una de las cuatro propuestas lanzadas en la VIII Legislatura, o sea, la de inclusión de una mención explícita a la construcción europea en la Constitución estatal ${ }^{55}$. Esa

51 LÓPEZ GUERRA, L.: «Hacia un concepto europeo de derechos fundamentales», RVAP, $\mathrm{n}^{\circ}$ 65, 2003.

52 JIMENA QUESADA, L.: Sistema europeo de derechos fundamentales, Madrid, Colex, 2006.

53 El derecho de voto de los extranjeros en las elecciones locales figuraba entre las sesenta proposiciones de François Hollande durante su campaña presidencial («Citoyenneté et droit de vote des étrangers», Vie publique, 12 abril 2012, (http://www.vie-publique.fr/politiques-publiques/politique-immigration/droit-vote/, visitado el 17 de julio de 2012).

54 PAUNER CHULVI, C.: «Los derechos de participación política de los ciudadanos españoles en el exterior», Régimen jurídico de la ciudadanía española en el exterior (ed. J. L. BLASCO DÍAZ), Valencia, Tirant lo Blanch, 2010, pág. 110-111: la citada autora recuerda el «profundo debate que, desde hace algunos años, se ha abierto en nuestro país sobre la posibilidad de otorgar primacía al criterio de la residencia sobre la nacionalidad. Esta novedad implicaría una revisión legislativa y constitucional muy profunda puesto que operaría en doble sentido haciendo posible el derecho de participación política de los inmigrantes que viven en un municipio español y negando el derecho a los españoles que viven en el extranjero»; y, de la misma autora, «Reflexiones constitucionales sobre la propuesta limitativa del derecho de sufragio activo de los emigrantes», Corts. Anuario de Derecho Parlamentario, $\mathrm{n}^{\circ}$ 19, 2007. Léase asimismo GARCÍA MAHAMUT, R.: «El voto de los residentes ausentes y la Ley 40/2006 del Estatuto de la Ciudadanía española en el exterior», en El informe del Consejo de Estado sobre la reforma electoral. Texto del informe y debates académicos, Madrid, Consejo de Estado/CEPC, 2009. 
inclusión, además de alinearse más ampliamente con el proceder de otros países miembros de la $\mathrm{UE}^{56}$, tendría más calado, en términos de compatibilidad y promoción del paralelo sentimiento constitucional y europeo, que la introducción del equilibrio presupuestario en el artículo $135 \mathrm{CE}$, por más que en ocasiones entendamos que la conciencia europea se despierta en mayor medida cuando se toca el bolsillo de la ciudadanía: sobre este punto, sin por supuesto atisbarse la posibilidad de un impuesto europeo sobre la renta de las personas físicas o de un impuesto europeo sociedades, incluso el ejercicio del margen de apreciación nacional para la subida de un recurso propio de la UE como es el IVA, se encuentra en la base de reacciones desde todos los frentes, y señaladamente desde la sociedad civil como destinataria última y víctima de este tipo de medidas anti-crisis. Por último, de las asimetrías en la Unión en materia de moneda única (países que forman parte de la eurozona y países que no) se colige que este diagnóstico relacionado con una idea de ciudadanía económica no es exacto; antes bien, la crisis económica general, y del euro en particular, parece suscitar más reticencias que adhesiones ciudadanas a Europa.

\section{LA RELATIVIZACIÓN DEL EJERCICIO DEL PODER CONSTITUYENTE SOBERANO Y LA RELEGACIÓN DEL LUGAR DE LA CIUDADANÍA}

Lo reseñado hasta ahora pone de manifiesto que el artículo $135 \mathrm{CE}$, tanto en su versión de 1978 como en la revisada de 2011, se hace eco de un problema clásico que, a fin de cuentas, tiene que ver con la propia estabilidad político-económica o, si se prefiere, la existencia y no quiebra, del Estado. De hecho, la circunstancia de que España se haya visto compelida a introducir de modo más explícito esa «regla de oro» del equilibrio presupuestario en el Texto constitucional supone una forzada restricción de la soberanía económica que va más allá de la voluntaria cesión de competencias soberanas articulada a través de la base habilitante del artículo 93 CE: como telón de fondo se critica el alarde de dominación que, a modo de G-2 del eje franco-alemán ${ }^{57}$, ha acarreado la reforma

55 GARCÍA ESCUDERO, P.: «La acelerada tramitación parlamentaria de la reforma del artículo 135 de la Constitución (Especial consideración de la inadmisión de enmiendas. Los límites al derecho de enmienda en la reforma constitucional)», $T R C, \mathrm{n}^{\circ} 29,2012$, la citada autora subraya «la ironía de que por la puerta falsa de la reforma del artículo 135 se haya introducido en la Constitución la primera mención a la UE (e incluso, según De Esteban, a las Comunidades Autónomas como un hecho adquirido, mientras que hasta ahora la mención no era más que una promesa de futuro)» (p. 198).

56 Una aproximación comparada en LLOPIS CARRASCO, R.M.: «Las “cláusulas Unión Europea” en las Constituciones de los Estados como control de constitucionalidad de la integración europea: seguridad jurídica v. cheque en blanco», Cuadernos Constitucionales de la Cátedra Fadrique Furió Ceriol, núm 30-31, 2000.

57 Mientras, como se dijo, la Constitución alemana ya contiene esa «regla de oro», Francia curiosamente no habría secundado el ejemplo: RUIZ RUIZ, J.J., y SÁNCHEZ NAVARRO, A.: «El debate sobre la consagración constitucional de la estabilidad presupuestaria en Francia», TRC, nº 29, 2012, pág. 219-220: de la crónica de dichos autores se desprende además que la idea de «banalización» de la reforma constitucional en Francia (más de una veintena desde la adopción de la Constitución vigente de 1958), que ha conllevado por ejemplo que la introducción del principio de equilibrio presupuestario en el artículo 34 de la Constitución francesa en 2008 todavía no haya sido desarrollado técnicamente, ni haya prosperado el nuevo proyecto guberna- 
del artículo $135 \mathrm{CE}^{58}$. Adicionalmente, esa renuncia de soberanía al aceptar la imposición de la reforma del artículo 135 CE no se ha visto acompañada de la expresión de la voluntad del titular de la soberanía, habiendo llegado a plantearse un recurso de amparo por parte de grupos parlamentarios minoritarios en el que no sólo criticaban el procedimiento acelerado de reforma sino asimismo la reconducción sustancial de la modificación constitucional al mecanismo agravado del artículo $168 \mathrm{CE}$, que habría comportado la ineludible consulta popular ${ }^{59}$.

Sin duda, en ese economicismo timorato de que ha hecho gala España ha pesado sobremanera el parangón con la vulnerabilidad económica de países como Grecia e Italia, que han debido saldar asimismo primas de riesgo político aceptando, respectivamente, la renuncia a convocar un referéndum susceptible de rechazar las exigencias europeas o la renuncia a convocar unas elecciones de las que emergieren líderes sin el perfil tecnócrata requerido desde Bruselas: como es sabido, en ambos casos se ha generado la impresión de

mental de reforma presentado por el Gobierno galo en marzo de 2011, puede ser trasladada a España, por los motivos que se critican en la presente contribución.

58 Esa percepción también se tuvo desde el extranjero, como se expone en el artículo de FIORI, S.: «In Spagna Psoe et PP votano insieme la riforma della costituzione», http://www.loccidentale.it/node/109366 (3 septiembre 2011, visitado el 2 de enero de 2012): «Era el 16 de agosto cuando la cancillera alemana, Angela Merkel, y el presidente francés, Nicolas Sarkozy, avanzaban la propuesta según la cual los países de la eurozona tenían que introducir la obligación del equilibrio presupuestario en sus constituciones, a ser posible durante 2012. (...) Confianza por parte de los mercados (....) Pero asimismo confianza por parte de la zona euro, o más bien del eje franco-alemán, que ahora más que nunca constituye un mini G2 en el seno de la $\mathrm{UE}$.

59 Mediante el Auto del Pleno del TC nº 9/2012, de 13 de enero de 2012 (cuenta con tres votos particulares), se inadmite el recurso de amparo interpuesto por don Gaspar Llamazares Trigo y doña Nuria Buenaventura Puig, Diputados del Grupo Parlamentario Esquerra Republicana-Izquierda Unida-Iniciativa Per Catalunya Verts en el Congreso de los Diputados, sobre resolución de la Mesa del Congreso de los Diputados, de 30 de agosto de 2011, acuerdo de la Mesa del Congreso de los Diputados, de 2 de septiembre de 2011, acuerdo del Pleno del Congreso de los Diputados, de 30 de agosto de 2011, y acuerdo de la Mesa del Congreso de los Diputados, de 1 de septiembre de 2011, recaídos todos ellos en relación con la tramitación parlamentaria de la proposición de reforma del artículo 135 CE. En el Antecedente 3 del Auto puede leerse lo siguiente: «3. En la demanda se denuncia la vulneración del derecho contenido en el artículo 23.2 CE en los siguientes términos: Los recurrentes ponen de manifiesto la, a su juicio, inadecuada tramitación de la proposición de reforma constitucional conforme al procedimiento ordinario del artículo $167 \mathrm{CE}$, pues la reforma propuesta no se limita al artículo $135 \mathrm{CE}$, sino que supone una modificación encubierta del título preliminar de la Constitución Española, singularmente en cuanto el apartado tercero del precepto prevé que: "los créditos para satisfacer los intereses y el capital de la deuda pública de las Administraciones se entenderán siempre incluidos en el estado de gastos de sus presupuestos y su pago gozará de prioridad absoluta”. La previsión, siempre a juicio de los recurrentes, supone introducir un valor superior a los de justicia y equidad, con el resultado de que la cláusula social del Estado queda menoscabada al quedar éste como un "Estado rehén" de las eventuales condiciones que los mercados vayan imponiendo para la financiación pública. Con estos presupuestos, la reforma de la Constitución, además de la reforma encubierta del título preliminar, en especial de su artículo 1.1, supone una rebaja del nivel de protección de los derechos fundamentales (se alude, ad exemplum, al derecho a la tutela judicial efectiva, en cuanto que los recursos destinados a la Administración de justicia quedan condicionados al pago prioritario de los intereses y capital de la deuda o de la vertiente prestacional del derecho a la educación, por las mismas razones). En definitiva, la utilización del procedimiento de reforma ordinario, además de inadecuada por razones materiales, supone una merma en las facultades de participación de los Diputados y de los propios ciudadanos por cuanto se eliminan las preceptivas convocatorias electoral y del referéndum previstas en el artículo $168 \mathrm{CE}$ » 
que la UE ha quitado (Yorgos Papandreu y Silvio Berlusconi) y puesto (Lucas Papade$\operatorname{mos}^{60}$ y Mario Monti) Gobiernos a su antojo, lo cual hace difícilmente resistible el test de democraticidad, por más deseadas o controvertidas que se mostrasen aparentemente la salida o la entrada de los líderes en cuestión ${ }^{61}$.

Realmente, reformas constitucionales nacionales como la operada en España del artículo 135 CE reflejan la incapacidad de los Veintisiete para inscribir la regla de oro del equilibrio presupuestario en el propio Derecho primario o constitucional de la UE mediante la reforma de los Tratados; y la anómala sustitución de los gobernantes secundada en países como Grecia o Italia son asimismo trasunto de la incapacidad de los Veintisiete para erigir un verdadero Gobierno económico de la UE igualmente a través de la revisión de los Tratados. Los dos elementos mencionados constituyen el corolario de otra debilidad de la UE, a saber, la inexistencia de una sanción de expulsión del club de los Veintisiete a aquellos socios que incumplan gravemente las normas comunes (especialmente, económicas de convergencia y políticas de respeto de la democracia y los derechos humanos) ${ }^{62}$, más allá de la retirada voluntaria establecida recientemente (con motivo del Tratado de Lisboa — artículo 50 TUE). Ante semejante carencia la UE, y especialmente los socios que encarnan el motor de la construcción europea (de nuevo, el eje francoalemán), tampoco está dispuesta a presionar con sanciones parciales que debiliten asimétricamente el bloque comunitario (por ejemplo, forzar la salida de la eurozona): la dinámica política parece consistir en la opción a favor de un debilitado pero irreversible becho comunitario, frente a una fuerte pero versátil soberanía nacional.

Desde luego, la lectura de esas deficiencias se perfila bastante nociva desde la perspectiva de las categorías y los bloques clásicos del Derecho constitucional nacional. Y el panorama tampoco se revela halagüeño en clave de emergente Derecho constitucional europeo. Además, se ha generado una paradójica impresión: la Constitución económica nacional se ve reforzada con la asunción de parámetros europeos frente a una incompleta Constitución económica europea, mientras que la ausencia de Unión política no impide que desde la UE se orquesten débiles Gobiernos nacionales europeístas. Así, ante la so-

60 Luego sustituido por A. Samarás tras una última convocatoria electoral celebrada el 17 de junio de 2012.

61 IÑARRITU IBARRECHE, B.: «Crónica comunitaria: la actualidad institucional y económica de España en el marco de la Unión Europea», Cuadernos Europeos de Deusto, no 46 (monográfico sobre Legitimidad democrática en la Unión Europea), 2012, pág. 218: «El desánimo se acrecienta con la constatación de que los gobiernos elegidos democráticamente en Grecia e Italia han sido sustituidos por gobiernos de tecnócratas, cuando estos cambios han sido forzados por la apuesta de austeridad y recortes, que puede resultar nefasta para las Economías más débiles de la Unión».

62 Una vez que el procedimiento de sanción consistente en suspensión de derechos de voto (cuando exista un «riesgo claro» de que un Estado miembro viole gravemente los valores de la Unión) introducido por el Tratado de Niza (artículo 7 TUE, que mantiene su contenido y numeración tras el Tratado de Lisboa) se ha mostrado poco operativo, cabe mencionar que con remisión a dicho artículo 7 TUE la Comisión hizo pública el 17 de enero de 2012 su decisión de iniciar un procedimiento de infracción contra Hungría sobre tres cuestiones previstas en la reforma constitucional húngara: la independencia del Banco central nacional, el adelanto de la edad de jubilación de los jueces y la independencia de la autoridad encargada de la protección de datos (sin perjuicio de la eventual sustanciación del procedimiento ante el Tribunal de Justicia, su iniciación ya provocó la comparecencia del Primer Ministro húngaro Viktor Orbán ante el Parlamento Europeo el 18 de enero de 2012 y una reunión de aquél con el Presidente de la Comisión Europea Durao Barroso el 24 de enero de 2012). 
lidez de la «Constitución económica» nacional se resienten el instituto de la reforma constitucional, la organización de los poderes y la defensa de los derechos fundamentales a nivel estatal, cuando teóricamente el mayor grado de integración económica (frente a la deficitaria integración política) habría de generar una dinámica inversa.

Como conclusión, la reforma del artículo 135 CE pone de manifiesto no únicamente la relativización del ejercicio del poder constituyente por los representantes de la soberanía popular (un ejercicio soberano claramente limitado desde el exterior), sino igualmente la relegación del lugar del titular de dicha soberanía (un pueblo soberano notoriamente coartado en su protagonismo). El caso es que, por la fuerza de las cosas europeas (de la res publica europea) bajo tutela del Banco Central Europeo ${ }^{63}$ y por la dinámica arrolladora de los mercados ${ }^{64}$, el demos no sólo queda relegado en el ámbito interno en el ejercicio de sus derechos políticos fundamentales (dimisión y previa renuncia de Papandreu a efectuar consulta popular sobre el rescate en Grecia, ausencia de convocatoria de elecciones en Italia para la selección del primer Gobierno tecnócrata encabezado por Monti, y decisión de los dos grandes partidos mayoritarios de apear a las minorías parlamentarias ${ }^{65}$ y al pueblo español del recorrido de la reforma «exprés» del artículo $135 \mathrm{CE}$ ), sino también en las posibles formas de participación democrática en el terreno europeo (recuérdese que, a diferencia de la existencia de elecciones al Parlamento europeo desde 1979, la institución de un referéndum europeo no llegó a figurar siquiera en el Tratado constitucional de 2004 ni se incluyó en el Tratado de Lisboa ${ }^{66}$, que se limitó a establecer una iniciativa legislativa ciudadana europea cuyo desarrollo normativo derivado es reciente y de incierto impacto ${ }^{67}$ ).

63 PISARELLO PRADOS, G.: «Reforma constitucional y crisis: crónica de una regresión», Jueces para la democracia, $\mathrm{n}^{\circ} 72$, 2011, pág. 6-7: tras cuestionarse si la modificación del artículo 135 CE habría respondido, más que a una reforma europea, a una reforma para la periferia europea, el citado autor critica que «cuando se piensa, en efecto, en el poder de reforma que ha impulsado la última modificación constitucional, es difícil limitarse al papel formal desempeñado por las Cortes Generales. El propio acuerdo alcanzado por los partidos mayoritarios de ámbito estatal apelaba a la necesidad de lanzar una señal a los "mercados", a los "inversores" y al "Banco Central Europeo”. Estos actores han aparecido revestidos, así, de un poder de reforma tácito, con una capacidad normativa superior, incluso, a la del poder de reforma explícito, formal».

64 RIDAURA MARTÍNEZ, M.J.: «La reforma del artículo 135 de la Constitución: ¿Pueden los mercados quebrar el consenso constitucional?», TRC, $\mathrm{n}^{\circ} 29,2012$, pág. 259: la citada autora entiende que, salvados incluso los problemas de inconstitucionalidad del procedimiento de reforma, «no parece que las exclusivas exigencias del interés de los mercados puedan justificar una reforma de la Constitución que sacrifique el consenso constitucional».

65 GARCÍA ESCUDERO, P.: «La acelerada tramitación parlamentaria de la reforma del artículo 135 de la Constitución (Especial consideración de la inadmisión de enmiendas. Los límites al derecho de enmienda en la reforma constitucional)», ya cit., pág. 198: la autora concluye que «el procedimiento utilizado para la tramitación de la Proposición de reforma del artículo 135 de la Constitución no ha sido el adecuado. No sólo desde el punto de vista puramente formal: se han reproducido algunas quejas de las minorías parlamentarias sobre la ausencia de negociación con ellas por parte de los dos grupos mayoritarios, autores de la iniciativa, lo que ha propiciado la inexistencia de consenso, expresada mediante la legítima votación en contra o a través de la no participación en su aprobación».

66 En la doctrina ya se había planteado con anterioridad la pertinencia de una consulta popular europea para cuestiones «constitucionales» a escala de la UE, señaladamente para algunas reformas de los Tratados: así, AUER, A., y FLAUSS, J.F. (coords.): Le référendum européen, Bruxelles, Bruylant, 1997; asimismo FREIXES SANJUÁN, T. «El futuro de Europa y la Gobernanza europea», http://www.futuroeuropa.es/documentos/tfreixes000402.pdf, pág. 3 (consulta: 6 mayo 2012).

67 BILBAO UBILLOS, J.M: «La iniciativa ciudadana europea (art. 11.4 TUE)», Cuadernos Europeos de Deusto, $\mathrm{n}^{\circ} 46$ (monográfico sobre Legitimidad democrática en la Unión Europea), 2012, pág. 82: «No creo que pue- 


\section{REFLEXIONES FINALES: LA REFORMA CONSTITUCIONAL DE 2011 COMO AGRAVIO COMPARATIVO Y SIGNO DE EUROPEIZACIÓN DE LA FUNCIÓN CONSTITUYENTE}

Llegados a este punto, la reforma del artículo 135 CE se presenta ciertamente altisonante al elevar la estabilidad presupuestaria al rango de «valor que justifica su consagración constitucional», en una especie de nueva teoría de los valores constitucionales, adicionalmente sobredimensionada al consagrar tal valor a la luz del artículo 1.1 de la Carta Magna. Se ha pretendido, sin duda, introducir una reforma constitucional europeizante de naturaleza meramente simbólica y carácter innecesario en comparación con otras reformas «pendientes» más apremiantes ${ }^{68}$, como la propia mención genérica y explícita a la construcción europea en la Carta constitucional española, en el sentido analizado en el citado Informe del Consejo de Estado de 2006 sobre las modificaciones de la Constitución.

El agravio comparativo resulta todavía más perceptible y acentuado al confrontar la modificación del artículo $135 \mathrm{CE}$ no sólo con esas otras reformas constitucionales, sino al compararlo con el mayor pragmatismo de la europeización de las reformas de los Estatutos de Autonomía españoles o de las reformas de los Consejos regionales italianos, pues en estos dos últimos supuestos se sanciona el reconocimiento progresivo de las regiones de los Estados miembros en los procesos decisorios europeos ${ }^{69}$, tras el turning point del Tratado de Maastricht (con ulteriores desarrollos en el Tratado de Lisboa) que comportó el paso del «regionalismo funcionalista» al «regionalismo institucional» ${ }^{70}$.

Con semejante proceder reformista, la dirección política de los Gobiernos nacionales encuentra una vez más una gran coartada en Europa en situaciones de debilidad de aquéllos, ora por la ya clásica organización de la Presidencia semestral (aparentemente modulada por un Presidente del Consejo Europeo, débil y poco relevante hasta la fecha), ora por una participación gradual de los Parlamentos nacionales para reducir el déficit democrático (el Consejo Europeo sigue siendo quien manda), ora ya incluso... ¡determinando la fase descendente a través de reformas constitucionales que ejecutan supuestos mandatos europeos! En esta línea, si la función de dirección política del Gobierno suele tener como elemento fuerte de identidad el anuncio de un paquete importante de medidas legislativas (y, en su caso, de incorporación de tratados internacionales) por parte

da hablarse de un antes y un después de la entrada en escena de la iniciativa ciudadana europea. O de un cambio radical en la forma de hacer política en la UE. Albergo serias dudas incluso sobre la virtualidad de esta nueva herramienta para revertir la tendencia al progresivo distanciamiento entre los ciudadanos y las instituciones europeas. No va a ser fácil involucrar a ciudadanos de diferentes países en un proyecto común».

68 LÓPEZ AGUILAR, J.F.: «De la Constitución “irreformable” a la reforma constitucional "exprés”", $T R C, \mathrm{n}^{\circ}$ 29, 2012, pág. 217: sugiere que la reforma del artículo 135 CE genera una «nueva situación» que puede abrir «cauce a una nueva etapa de plena maduración democrática en la que poder abordar reformas que acometan las viejas cuentas pendientes del ya "italianizado" debate sobre la reforma constitucional en España (Europa, CCAA, Senado y sucesión a la Corona)», así como otras cuestiones «exigidas por la demanda inapelable de una mejor imbricación entre la democracia representativa y la participativa de toda la ciudadanía».

69 Véase ORDÓÑEZ SOLÍS, D.: «Las relaciones entre la Unión Europea y las Comunidades Autónomas en los nuevos Estatutos de Autonomía», Revista d'estudis autonòmics i federals, no 4, 2007.

70 FASCONE, C.: «L'europeizzazione dei Consigli regionali. Il caso dell'Emilia-Romagna», Studi parlamentari e di política costituzionale, $\mathrm{n}^{\circ}$ 167-168, monográfico sobre Le riforme dei regolamenti dei Consigli regionali, a cargo de E. GIANFRANCESCO y N. LUPO (1ㅇ- $2^{\circ}$ trimestre 2010), p 163-164. 
del Presidente del Gobierno con ocasión de su investidura, la actual X Legislatura se ha visto marcada por una extraña dirección política identificada en torno a la reforma del artículo 135 CE que certificaba el final del segundo mandato del Presidente Rodríguez Zapatero y daba paso a la investidura del Presidente Rajoy Brey.

Ahora bien, pese a ese concierto coyuntural entre los dos grandes partidos, con la reforma constitucional como signo del traspaso de poderes entre el Gobierno cesante y el Gobierno entrante, lo cierto es que el liderazgo gubernamental español en el ámbito de la UE (incluso en materia económica) queda tan en entredicho como el desdibujado carisma de Van Rompuy, quien ante la inexistencia de un verdadero Gobierno económico europeo se convertía paradójicamente en un débil «doble» Presidente del Consejo Europeo y de las Cumbres de Jefes de Estado y de Gobierno de la Eurozona en el segundo semestre de $2011^{71}$. En términos reales, por tanto, la reforma del articulo 135 CE no ha venido impuesta por un inexistente Gobierno económico «bicéfalo» (de los Veintisiete y de los Diecisiete al tiempo) ni por un asimétrico concierto de Jefes de Estados y de Gobierno. En el terreno doctrinal, se nos suele hacer la boca grande cuando criticamos el déficit democrático en el engranaje institucional europeo, pero frecuentemente se nos queda pequeña cuando ese déficit se mimetiza a escala, nada más y nada menos, que constitucional interna; se me antoja, a modo de crítica y políticamente incorrecta percepción un tanto maquiavélica, que la academia aparenta ser un tanto «mercenaria» o excesivamente complaciente con la clase política dominante en el contexto de esta dinámica constitucional europea.

Bajo esta óptica de la legitimidad democrática, la crítica federalista según la cual las instancias europeas carecerían de poder y de recursos, mientras que los Estados dispondrían de una autoridad y unos medios ilimitados, se ve forzada o superada por los acontecimientos, quedando la gobernanza económica y la gestión de la crisis (con el poco éxito al que estamos asistiendo) a expensas del todopoderoso Banco Central Europeo, que consagra millones de euros a refinanciar a los bancos sin depender, ni de los Gobiernos ni de los electores de la Unión ${ }^{72}$. La modificación del artículo $135 \mathrm{CE}$, en suma, ha respondido a la presión conjunta de ese poder fáctico de la banca europea y de la pujante maquinaria político-económica alemana, en donde emerge una suerte de neonacionalis-

71 El reflejo de la Europa de las velocidades en materia de unión económica y monetaria, con las reuniones excepcionales de las denominadas «Cumbres de los Jefes de Estado y de Gobierno de la Eurozona» (de los Diecisiete) en paralelo a los Consejos Europeos de los Veintisiete, quedó oficializada tras las Conclusiones del Consejo Europeo celebrado el 23 de octubre de 2011, en donde se señalaba que «el Presidente de la Cumbre del Euro será designado por los Jefes de Estado o de Gobierno de la zona euro a la vez que el Consejo Europeo elija a su presidente y para el mismo período». Así, en la Cumbre convocada el 26 de octubre, los Diecisiete decidieron mejorar la estructura del gobierno de la Eurozona, acordando que las «Cumbres del Euro» debían celebrarse, como mínimo, dos veces al año, «en momentos clave del ciclo anual de gobierno económico y, si es posible, tras las sesiones del Consejo Europeo».

72 Esta percepción crítica en HALIMI, S.: «Fédéralisme à marche forcée», Le Monde Diplomatique, $\mathrm{n}^{\circ}$ 700, julio 2012, pág. 1. Una critica doctrinal con similar espíritu ya en ELGIE, R.: «The politics of the European Central Bank: principal-agent theory and the democratic deficit», Journal of European Public Policy, vol. 9, $\mathrm{n}^{\circ} 2$, abril 2002 .

73 Con tal enfoque, SARRAZIN, T.: Europa braucht den Euro nicht, Berlin, Deutsche Verlags-Anstalt, 2012: al propugnar que Europa no necesita el euro, el autor exhorta a la próspera Alemania a seguir una andadura en solitario sin aportar un céntimo más a sus socios mediterráneos, acusados de destruir Europa por su alergia al trabajo y su deriva presupuestaria. 
mo económico contrario a salvar el euro manteniendo a los países mediterráneos que habrían provocado su crítico estado ${ }^{73}$.

Con estos mimbres, seguramente la reforma constitucional española de 2011 deba consolidar nuestra obstinación en seguir hablando de reformulación de los postulados clásicos de la soberanía antes que de crisis de la soberanía para que, mutatis mutandis, nos sea dado aludir a una reformulación — antes que de crisis- de los postulados clásicos de la teoría constitucional, por cuanto la modificación del artículo 135 CE ha escenificado una internacionalización o europeización de la función constituyente y ha puesto en entredicho la imperante idea del procedimiento especial de reforma como causa de la rigidez constitucional.

$* * *$

TITLE: The 2011 amendment of the Spanish Magna Charta: overcoming clichés on constitutional taboo and rigidity

ABSTRACT: This essay suggests that the 2011 Constitutional Amendment (Art. 135) to include a debt ceiling provision and impose a balance budget standard in Spain has confirmed that economic forces and interests prevail in practice over theoretical solid constitutional principles, both at European and domestic levels. Indeed, some parallel paradoxes have emerged: firstly, the absence of a real European economic government (the asymmetric approach consisting of one European Council for 27 and one Euro Summit for 17) together with the weak position of a National government (governing without a parliamentary majority) bave nevertheless produced an «abuse» of constitutional provisions as an anti-crisis instrument. Secondly, the prominent economic and competition rules included in European Primary Law together with the material flexibility of the Spanish Economic Constitution have not been suitable to prevent from relativizing theoretical rigid revision procedures of European Treaties and Spanish special constitutional amendment procedure. The final conclusion is the need to strengthen both: the position of Citizenship/Demos at European and domestic level as well as the dogmatic foundation of the Theory of (European and National) Constitutional Law.

RESUMEN: El presente trabajo sugiere que la reforma constitucional de 2011 (art. 135) para incluir el limite máximo de endeudamiento e imponer la estabilidad presupuestaria en España ha confirmado que las fuerzas e intereses económicos prevalecen en la práctica sobre unos teóricamente sólidos principios constitucionales, tanto a nivel europeo como nacional. En efecto, se han producido en paralelo algunas paradojas: en primer lugar, la ausencia de un real Gobierno económico europeo (con un asimétrico enfoque consistente en un Consejo Europeo de 27 y una Cumbre del Euro de 17) al lado de la débil posición de un Gobierno nacional (sin mayoría parlamentaria), han sido capaces no obstante de operar un «abuso» de las disposiciones constitucionales como instrumento anticrisis. En segundo término, las contundentes normas económicas y de competencia incluidas en el Derecho Europeo primario, junto con la material flexibilidad de la Constitución económica española, no se han mostrado tampoco adecuadas para impedir la relativización de los teóricamente rígidos procedimientos de revisión de los Tratados Europeos y del procedimiento especial de reforma constitucional en España. Se llega así como conclusión a la necesidad de reforzar: tanto la posición de la ciudadaníaldemos a nivel europeo e interno, como los fundamentos dogmáticos de la Teoría del Derecho constitucional (europeo y nacional).

KEYWORDS: flexibility and rigidity-constitutional pact and consensus-special revision procedures-constitutional amendment-economic constitution-economic government-democratic deficit and legitimacy-Europeanization of constitutional categories

PALABRAS CLAVE: flexibilidad y rigidez-consenso y pacto constitucional-procedimientos especiales de revisión-reforma constitucional-constitución económica-gobierno económico-déficit y legitimidad democráticos-europeización de categorías constitucionales

FECHA DE RECEPCIÓN: 20.06.2012 FECHA DE ACEPTACIÓN: 19.07.2012

UNED. Teoría y Realidad Constitucional, núm. 30, 2012, pp. 335-356. 